\title{
LA ACÚSTICA DE LA SALA DE ASAMBLEAS DEL PALACIO DE LAS NACIONES DE GINEBRA, DE LE CORBUSIER
}

\author{
(THE ACOUSTICS OF THE ASSEMBLY HALL OF THE PALACE OF THE NATIONS \\ OF LE CORBUSIER IN GENEVE)
}

Francesc Daumal i Domènech, Dr. arquitecto

Catedrático en la ETSAB

Colaboradores en la ETSAB:

Información y traducciones: Edith Savere y Jean François Bouju, arquitectos y estudiantes de 3. ${ }^{\mathrm{er}}$ ciclo.

Maqueta: Orlando Álvarez, Hernán Crespo, Juan José Mascaró y Edith Savere, arquitectos y estudiantes de 3. ${ }^{\text {"t }}$ ciclo.

Ecuación: Toni Isalgué, Dr. en Ciencias Físicas y Profesor Titular.

Fecha de recepción: $11-$ III - 94 ESPANA

RESUMEN

Le Corbusier tenía razón en sus planteamientos de la acústica de la Sala de Asambleas, pero, aun asi, no se hubiesen conseguido óptimamente sus objetivos. El público más alejado no habria podido entender a los oradores.

Este tema ha sido objeto de diferentes debates, y ahora el autor quiere aprovechar para hacer una reflexión.

\section{SUMMARY}

Le Corbusier was right in his approach to the acoustics of the Assembly Hall. Nevertheless, his objectives would not have been entirely attained; the audience in the farthest parts of the Hall would not have been able to hear the speakers.

This topic has been debated on various occasions and the author of this article offers another opinion.

\section{El Palacio de las Naciones a Concurso}

Si hacemos un resumen del proceso que se ha seguido, vemos que todo empieza en marzo del año 1926, cuando la Asamblea Extraordinaria de la Sociedad de las Naciones Unidas organiza un concurso para el proyecto de su nueva sede en Ginebra, donde además del Secretariado, hacía falta incluir una gran Sala de Asambleas.
El 5 de mayo de 1927, después de 64 sesiones dedicadas a examinar los proyectos presentados, el jurado decide asignar nueve premios (entre ellos el del proyecto de Le Corbusier y Pierre Jeannneret), y 18 menciones, transgrediendo las prescripciones del reglamento que establecía atribuir siete premios jerárquicamente diferentes. 


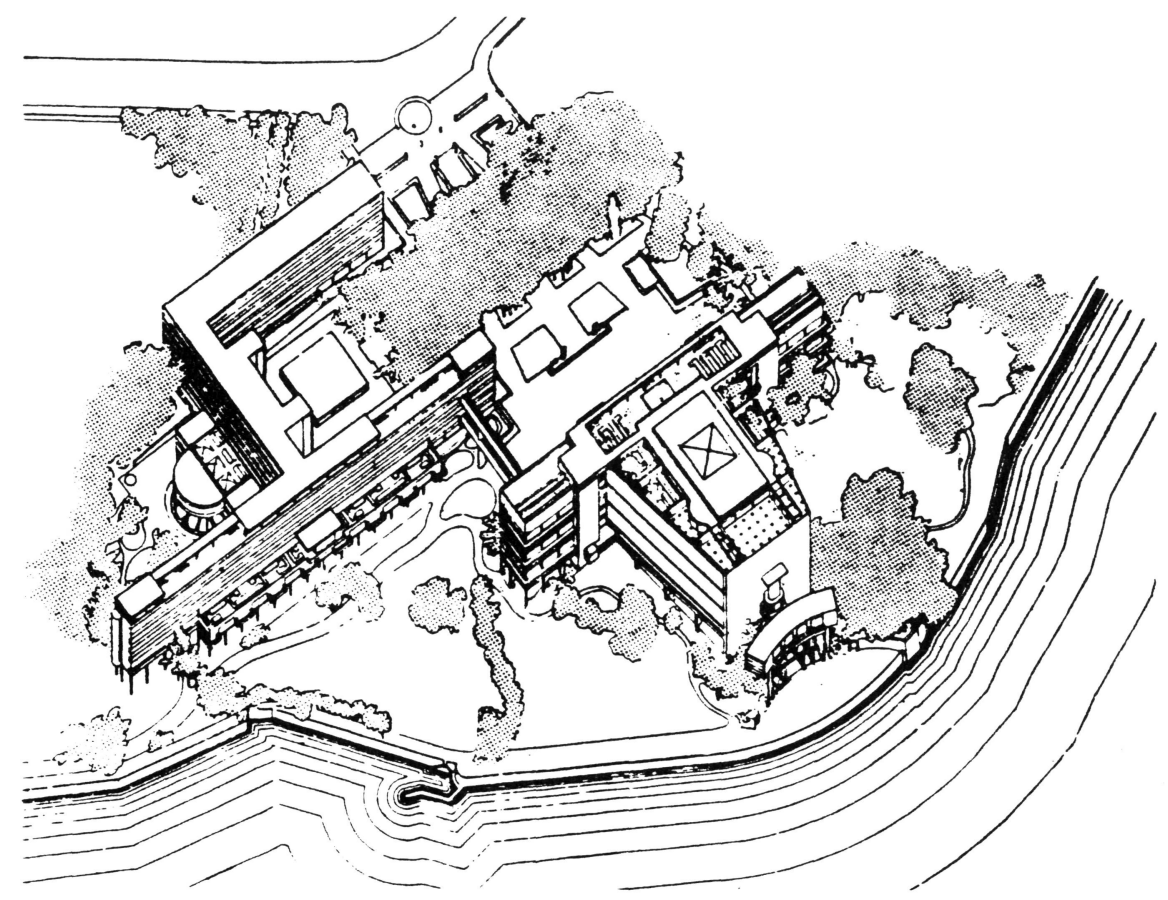

Isomeria del propecto presentado a concurso por Le Corbusier; con la Sala de Asambleas en primer término.

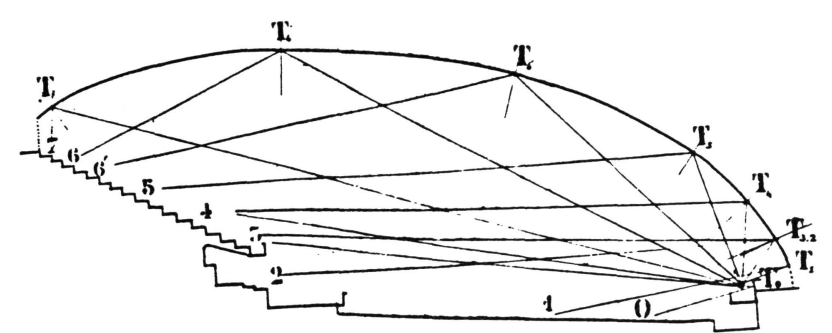

Trazado teórico del techo reflector, fijada la siluación del orador $y$ de las gradas. El falso techo, hasta el último centímetro, es explotado como reflector, y proyecta las ondas (siguiendo la ley de la incidencia) hacia los oídos de los auditores. La distancia entre el orador $T_{0} y$ el auditor $T_{7}$ es de 70 metros. Esta curva de falso techo no tiene nada que ver con las leyes de la estática.

$(A+B)-C<22 m$

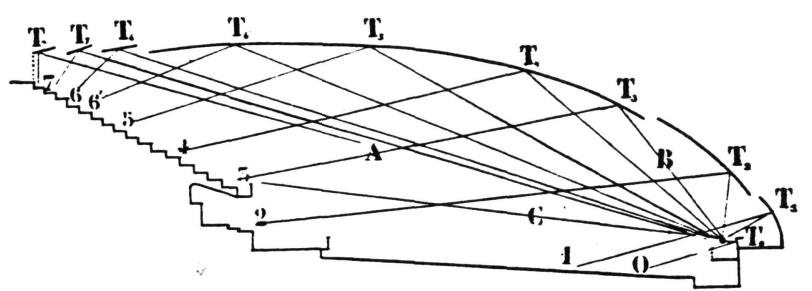

Una vez obtenida la curva teórica del falso techo anterior, es seccionada en diferentes puntos, y los elementos se bajan de forma que la altura total de la sala corresponde a la del edificio determinado por las alturas de las plantas de las alas de las comisiones. En resumen, se mantiene la misma curva (misma refracción de las ondas), pero la altura total de la sala baja unos seis metros.

Figuras y anotaciones de Le Corbusier donde explica la génesis del proyecto para la Sala de Asambleas.
En la carta ${ }^{1}$ del 25 de mayo de 1927 que Karl Moser (uno de los miembros del jurado) le envía a Huston, que era el Jefe de los Servicios Internos de la Sociedad de las Naciones, establece que:

La solución perfecta, respecto a la ubicación del edificio, la más satisfactoria, será la que la Sociedad de las Naciones encargue a Le Corbusier para la ejecución del proyecto en colaboración con la Sociedad de las Naciones, quizá mediante un arquitecto de confianza que aconseje y asista a las sesiones. Si me preguntáis nuevamente jpor qué Le Corbusier?... porque él es el único concursante que ha elaborado un proyecto con extrema conciencia desde el punto de vista de la ubicación, de la circulación interna y externa, desde el punto de vista funcional, de la acústica, de la iluminación diurna y nocturna, de la calefacción y desde el punto de vista de los costes... Ningún otro proyecto se ha enfrentado con las exigencias de las condiciones del concurso de una forma tan completa, intensa, clara y espiritual.

Por lo tanto, el jurado reconoce las virtudes de prever el comportamiento acústico en el proyecto presentado.

\section{El enfado de Le Corbusier}

Le Corbusier reacciona a la decisión del jurado, y envía una carta $^{2}$ a uno de los miembros del jurado, Hendrik Berlage, de fecha 6 de junio de 1927, donde, entre otras cosas, dice:

Tenemos el derecho a ser seleccionados porque nuestro proyecto (de acuerdo con la disposición para la utilización de los espacios interiores), es el más práctico,y la sala, que probablemente es la única que ofrece garantías para una buena acústica (sin la cual esta sala sería un desastre debido a sus notables dimensiones). 
Se establece pues la importancia de tener en cuenta la acústica dadas las grandes dimensiones que tendrá la Sala de Asambleas.

Pero este manifiesto interés por la acústica no es superficial para Le Corbusier, sino muy profundo. En este proyecto, Le Corbusier considera la acústica desde las propias fases iniciales del diseño y no como una corrección posterior a hacer.

Con esto hace falta reconocer a Le Corbusier como a uno de los precursores de lo que denominé como Arquitectura Acústica ${ }^{3}$.

\section{El papel de Lyon}

Fijémonos si es importante la acústica de la sala para Le Corbusier, que hasta hace intervenir en su favor a su consultor acústico Gustave Lyon, quien en la carta ' del 13 de junio de 1927, dirigida al Secretario General de la Sociedad de las Naciones, le dice:

\begin{abstract}
"He recibido con gran satisfacción la noticia de que el proyecto del Palacio de los señores Le Corbusier y Pierre Jeanneret, arquitectos de Paris, haya obtenido un Primer Premio en el Concurso Internacional de Arquitectura. Este proyecto prevé una Gran Sala, la concepción de la cual se hasa en las leyes acústicas que yo he formulado, y que los señores Le Corbusier y Pierre Jeanneret han aplicado de forma inteligente. Si me permito señalar a vuestra competencia esta particularidad, es porque en este caso se trata a mi entender, de una cuestión capital que sobrepasa absolutamente las cuestiones personales. Ciertamente, la bistoria de la arquitectura demuestra que a excepción de los teatros griegos (al aire libre sin techo), la acústica de las grandes salas, salvo en raras excepciones, es defectuosa, sobre todo en las salas parlamentarias, teatros liricos y salas para conciertos Las salas parlamentarias donde se escucha con dificultad, exigen de los oradores unas cualidades vocales muy particulares, que a menudo ponen de manifiesto los defectos de otros oradores de superior cualidad de pensamiento. .
\end{abstract}

Siguiendo con los estudios tanto experimentales como teóricos, be podido llegar a la formulación de las leves físicas precisas para la acústica de las salas, que libremente be becho conocer a todos los ingenieros o arquitectos que han querido preguntarme sobre este propósito. Por eso, hoy es más o menos posible corregir cualquier sala; pero corregir significa únicamente liberar estas salas de los ecos molestos. Al suprimir estas ondas molestas nos arriesgamos a privar a los auditorios de un cierto tanto por ciento del sonido emitido; la audición puede resultar más clara, pero con el riesgo de ser floja. Se suprimen asi los defectos, pero no se pueden aumentar las cualidades.

Hoy se pueden construir salas concebidas no exclusivamente en consideraciones de orden estético. Se pueden construir salas rigurosamente fundamentadas sobre las leyes de la acústica, y que permitan una audición igual desde todos los puntos de la sala ubicados a la misma distancia del orador. He construido actualmente una sala similar en París, la sala Pleyel. La demostración práctica de mis teorias son hoy un hecho consumado. Esta sala es para conciertos, con 3.000 localidades y con una profundidad de 50 metros..

Abora bien, la Gran Sala de la Asamblea General de la Sociedad de las Naciones es aún más grande. Mide 70 metros de profundidad. La Sociedad de las Naciones convoca cada año 2.600 personas con la finalidad de debatir, explicar y conversar. ¿Qué sería de los 2.600 convencionistas si se oyesen mal o a disgusto? No se podrian entender, ni explicarse, y la finalidad perseguida para la construcción del Palacio de las Naciones no se habría logrado.

(c) Consejo Superior de Investigaciones Científicas Licencia Creative Commons 3.0 España (by-nc)

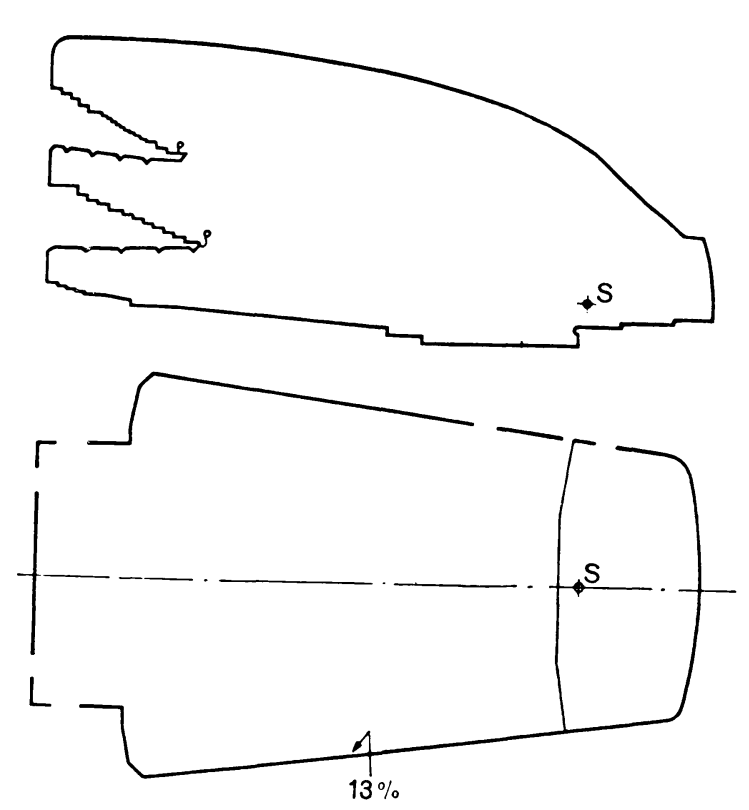

Alzado ye planta de la Sala I'le'ied de P'aris.

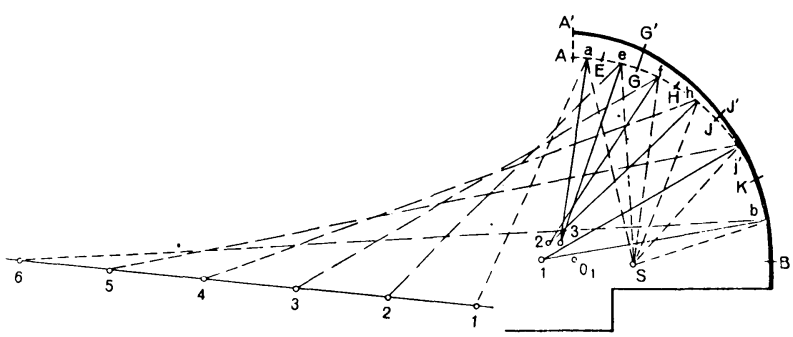

Wétodo ligen de e'puipolencialidad somora.

Existe, además, una gran confusión en las ideas del público y en particular de los arquitectos. Se cree que la acústica es un misterio. Si aún no se admite que las leves de la mecánica havan sido formuladas, menos se admite aún que lo sean ésas de la acústica. $Y$ se proyectan salas que la mayoría de las veces no son favorables a la audición, sino al contrario, notablemente antiacústicas. Me permito exponer a vuestra consideración los tres esquemas representativos:

a) Sala rectangular.

b) Sala circular.

c) Sala en forma de vano.

Las dos primeras producen un rumor intenso derivado de los ecos.

La última planta presenta el techo y los muros laterales pensados para conducir las ondas sonoras, acumularlas, reflejarlas rigurosamente sobre los espectadores y transmitir a los auditores sentados en las últimas localidades una masa sonora pura (sin rumor) de la misma calidad que la que recibirán los oyentes ubicados delante del orador. Permitirá discutir con las más sutiles inflexiones de la voz que llegarán integras y suficientemente fuertes a los auditores más alejados.

Las salas a) y b), una vez construidas, podrán ser corregidas más o menos bien, y con costes más o menos altos. Pero la audición será completamente alterada y el orador, como el auditor, se encontrará obligado a hacer cansados esfuerzos... 


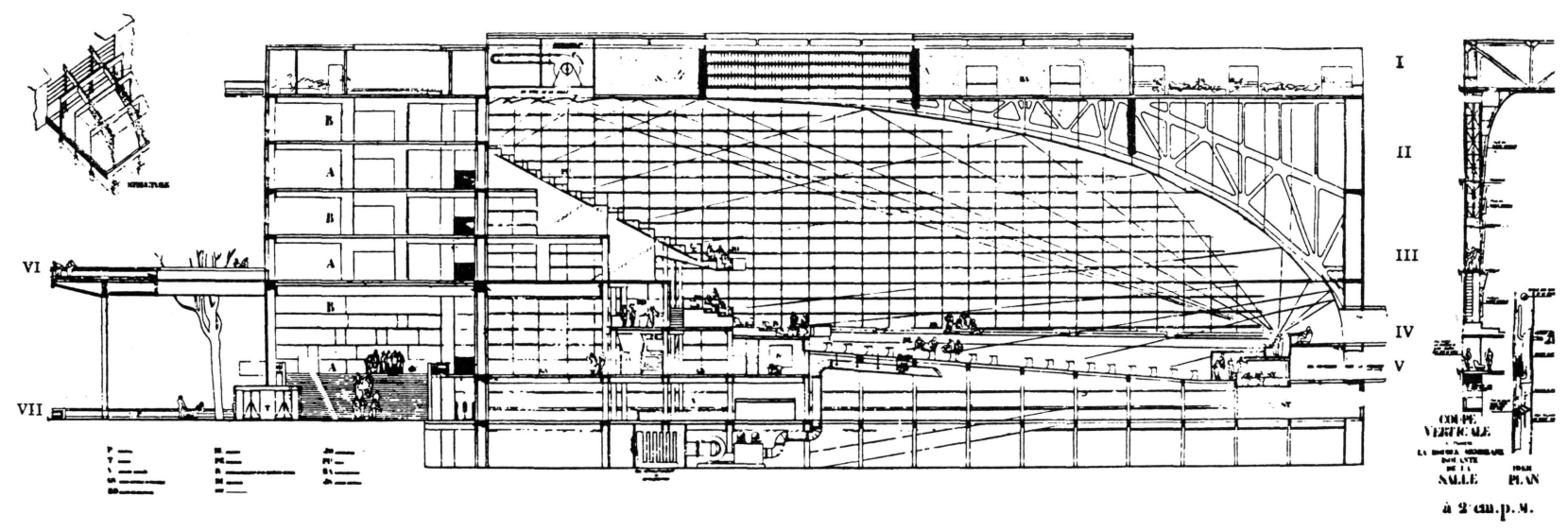

Sección acústica de la Sala de Asambleas, según el proyecto original de Le Corbusier

Para terminar quería sugeriros la idea — antes de que se tomen graves decisiones - de enviar a París personalidades competentes que, al visitar la Sala Pleyel actualmente acabada, podrian formarse sobre este problema una opinión absolutamente segura. Muy gustosamente me pondría a su disposición con tal de hacerles conocer las leyes que be descubierto, los medios para controlarlas y las conclusiones arquitectónicas de orden práctico que de ellas se deriven...

En este escrito de apoyo entusiasta, Gustave Lyon reconoce que el proyecto de Le Corbusier se basa en sus leyes acústicas.

Estas leyes son en la actualidad suficientemente conocidas ${ }^{5}$ dentro del método gráfico denominado Lyon para obtener la equipotencialidad sonora en el plano de la audiencia.

Hay que recordar que la deducción y aplicación del método de Lyon, además de las leyes ópticas de la reflexión, se fundamenta en que la cantidad de sonido reflejado es proporcional a la superficie de reflexión, y en el decrecimiento de la intensidad sonora según el cuadrado de la distancia.

Lyon se basa sobre todo en el plano curvado del techo del escenario, aunque como ahora sabemos, el equilibrio se consigue mejor al utilizar también sus paredes laterales.

Pero si Le Corbusier se basó en el método de Gustave Lyon, quizá este último no intervino en el proyecto, como lo creen Anzivino y Godoli ${ }^{6}$, que establecen:

Como resultado también de esta carta, Gustave Lyon no colaboró con Le Corbusier y Pierre Jeanneret en la elaboración del proyecto para el Palacio de la Sociedad de las Naciones, contrariamente a lo que a veces se lee en algunos articulos, sino que se limitó a darles algunos sugerimientos técnicos. Le Corbusier hace del resto un misterio por haber utilizado en el proyecto de la Sala de Asambleas los principios puestos a punto por Gustave Lyon.
Hasta el mismo Christian Zervos, entonces director de la revista Cabiers d'Art ${ }^{7}$, escribe a Berlage el 15 de noviembre de 1927:

"He pedido que del proyecto de Le Corbusier y Jeanneret se haga una cuestión de principios a favor del arte moderno. Como del justificante de esta manifestación, querría explicar, brevemente, que prescindiendo de la cuestión estética relativa a la fachada, el proyecto de Le Corbusier y Jeanneret presenta ventajas que van desde el punto de vista del respeto al ambiente, a la circulación tanto externa como interna, y a las proporciones y acústica de la Sala de Asambleas..."

La reivindicación de la acústica de la Sala es muy importante para Le Corbusier, sobre todo porque ve que, salvo contadas ocasiones, los otros proyectos premiados en absoluto la tienen en cuenta.

Por lo que parece, en un escrito publicado en los Cabiers d'Art, Le Corbusier aprovecha para devolverle el favor a Gustave Lyon.

Se sabe que después de la intervención de Lyon, la acústica de la Sala Pleyel de París era óptima para los auditores, pero no lo suficiente para los músicos, ya que todo el sonido que éstos emitían iba hacia el público y no quedaba nada para ellos. Por este motivo se reformó el escenario añadiéndole unas pantallas reflectoras para los ejecutantes ${ }^{8}$.

Unos párrafos de este artículo de Le Corbusier ${ }^{9}$ son suficientemente representativos para hacer patente el homenaje que rinde a quien es capaz de atentar contra la Academia de ese momento:

He aquí el valor histórico de la Sala Pleyel. Sin ambigüedad ni restricción, es verdadera... Esta verdad hará un camino flameante. Hay muchos cambios que el académico escogerá para la Sociedad de las Naciones, para mejorar el Palacio de las Naciones, porque no ba becho una sala acústica donde la depuración aparece como una obra de ingeniero, sino una sala borboniana sin tímpano, ni garganta, construirá en Ginebra una sala acústica bajo los dictados de un ingeniero. ¿Cómo pueden tolerar los responsables de la Sociedad de las Naciones que les den una sala donde nadie entiende los discursos? 


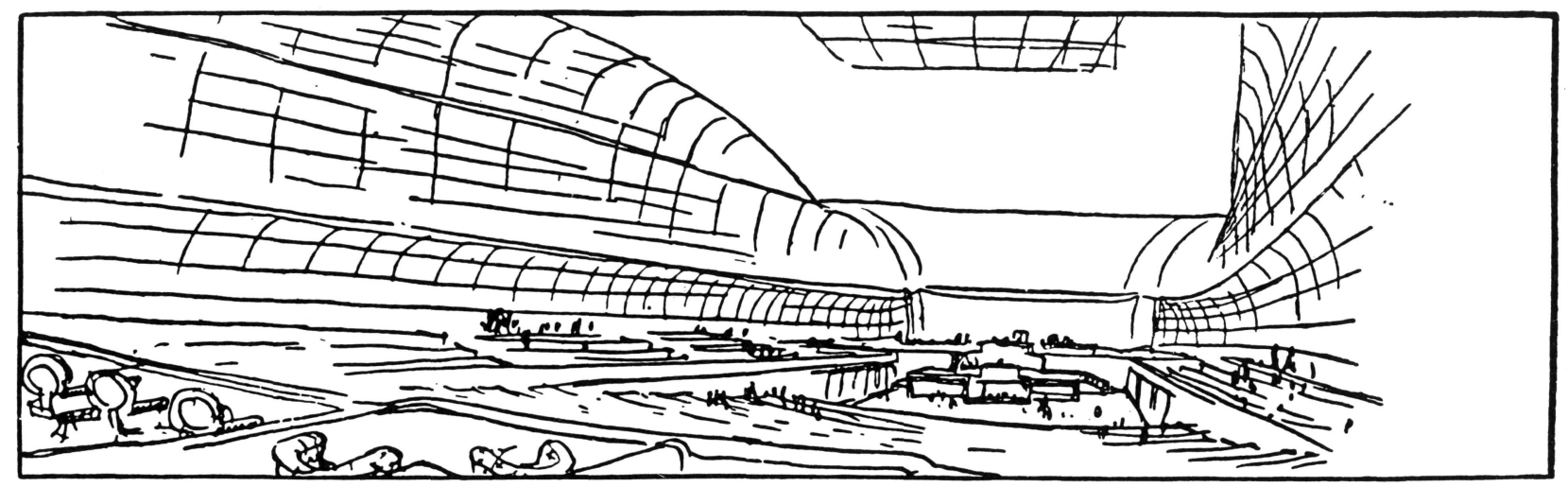

Esquemática y sugerente perspectiva interior de la Sala de Asambleas, existente en el proyecto original de Le Corbusier.

Seguro que en el mundo entero, todos los futuros propietarios de salas exigirán la máxima seguridad acústica. Y el número de salas Pleyel se multiplicará.

\begin{abstract}
Admitámoslo. ¿Qué consecuencias arquitectónicas tendremos? Contrariamente al sueño de las Academias, estas nuevas salas no podrán ser borbonianas; costarán el doble o el triple y no podrán ser más que corregidas, y en consecuencia muy distantes del rendimiento máximo. (Y los futuros propietarios de salas no tendrán el soberbio desinterés que la Sociedad de las Naciones ha manifestado para sus cosas, que constituyen la propia base de un problema de arquitectura). Estas nuevas salas serán modernas. Estamos dentro de un sistema biológico, donde todo son planos torcidos, superficies torcidas... He aqui la siniestra farsa jugada por el sabio Gustave Lyon al lirismo de las Academias.
\end{abstract}

Más tarde, Le Corbusier se vuelve hasta profesor de acústica al querer explicar cómo funciona la acústica de su Sala en el escrito "Une Maison, un Palais" ${ }^{10}$, donde en el apartado "Une grande salle pour 2.600 personnes, organe de visibilité et d'audition" establece entre otras cosas que:

Estas 2.600 personas se tienen que encontrar en unas condiciones de confort tales, que las dimensiones de la sala se vuelven enormes. Y aquí está el punto delicado, porque se trata de una sala para discursos, discusiones y disertaciones entre gente venida de las cuatro esquinas del mundo, que hablan idiomas diferentes, se entienden con dificultad, hacen debate sobre filosofias fuera de las contingencias, y discuten de la paz o de la guerra del mundo.

En la Cámara de Diputados de París, que es muy pequeña, se oye muy mal. Entonces, desde la revolución del 89 se ha inventado el estilo de tribuna y cada época ha tenido sus grandes ruiseñores con una garganta apta para producir efectos oratorios. Asi se han puesto a gobernar con efectos oratorios.

El pensamiento no reside en la garganta. La garganta no tiene siempre la facultad de gobernar. Y en Ginebra, teóricamente se han de tener más en cuenta unos pensamientos provenientes de la cabeza que no de la garganta.

Y en Ginebra, las gigantescas dimensiones de la sala nos anuncian el desastre irremediable si se construye según los medios, las recetas y los cánones de la Academia..

Aun así, las leyes de la acústica nos introducen en un orden que ya no es estático (ley de la gravedad con todas sus consecuencias de sistemas verticales, de uniones equilibradas, etc.), sino en un orden que es más bien biológico y con consecuencias formales que nada tienen en común con las de un sistema estático..

(c) Consejo Superior de Investigaciones Científicas

Licencia Creative Commons 3.0 España (by-nc)
Estas leyes son sencillas, comprensibles hasta para los niños, como son sencillas las leyes de este mundo. Lo que no es sencillo es descubrirlas, formularlas y hacer un sistema entero.

Esta es la obra muy reciente de Gustave Lyon.

Precisamos aún un punto: el verano de 1927 que siguió el veredicto del jurado del concurso, todo el mundo emitió múltiples y contradictorias opiniones respecto de la acústica. Nunca el problema había sido tan grande ni urgente, nunca la confusión fue tan desmesurada. Estos grandes errores servían de martillos y nadie era capaz de marcar los golpes. Asi un sabio fisico decretó que el sonido no podía llegar con suficiente fuerza más allá de los 30 metros (nuestra sala tiene 70); que el sonido no podría alimentar un volumen superior a los 20.000 metros cúbicos (nuestra sala tiene 40.000), etc.

Pero este asunto no termina aquí. Le Corbusier y Jeanneret presentan al presidente del Consejo de las Naciones un recurso ${ }^{11}$, de fecha 2 de julio de 1931 y que parece que es el segundo, donde denuncian el plagio de sus ideas en el proyecto finalmente encargado, y exponen para la Sala entre otros temas:

su esquema de reflexiones estudiadas según los nuevos principios de la acústica.

\section{La acústica a debate}

Después de todo lo que se ha dicho, se tendrá que ver finalmente cómo estos nuevos principios de la acústica son aplicados en el proyecto de la Sala.

Si nos fijamos en el trazado de la curva continua del falso techo de partida del proyecto ${ }^{12}$, que por lo que parece Le Corbusier hizo de acuerdo con las leyes de Lyon, nos aparece una curva de regresión de forma elíptica definida por la ecuación:=

$$
((x-66,6) / 157,3)^{2}+((y+242,3) / 284)^{2}-1=0
$$




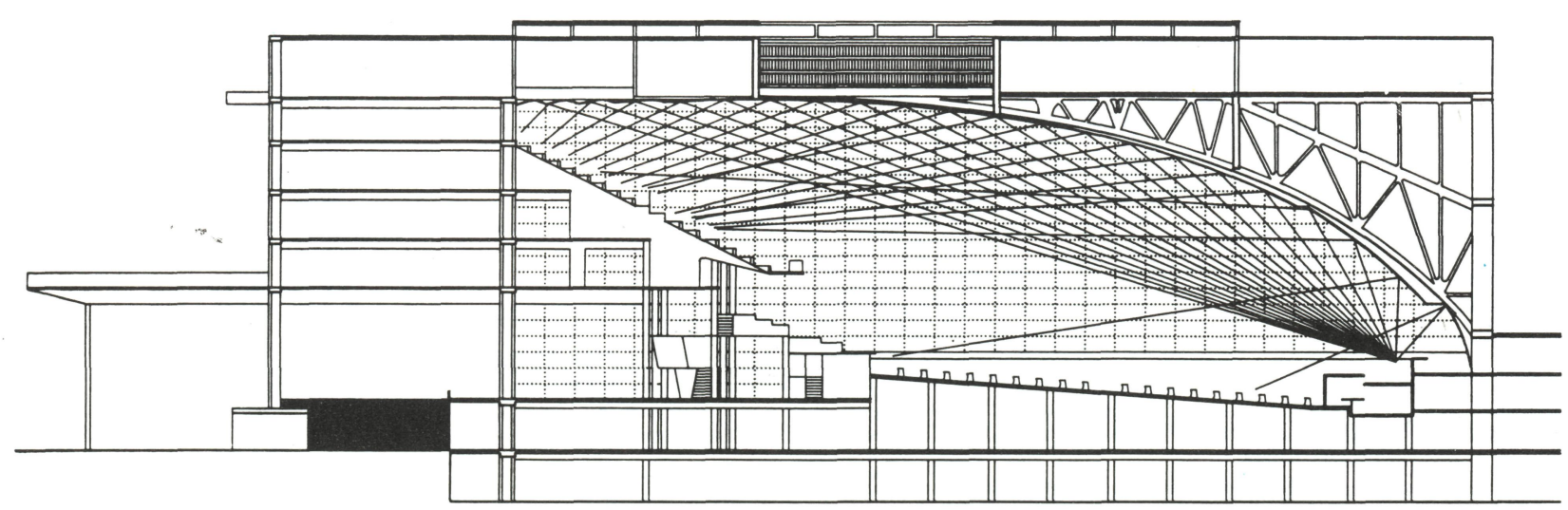

Los métodos del Ray-tracing, permiten boy obtener nuevas versiones del comportamiento acústico de la Sala de Asambleas.
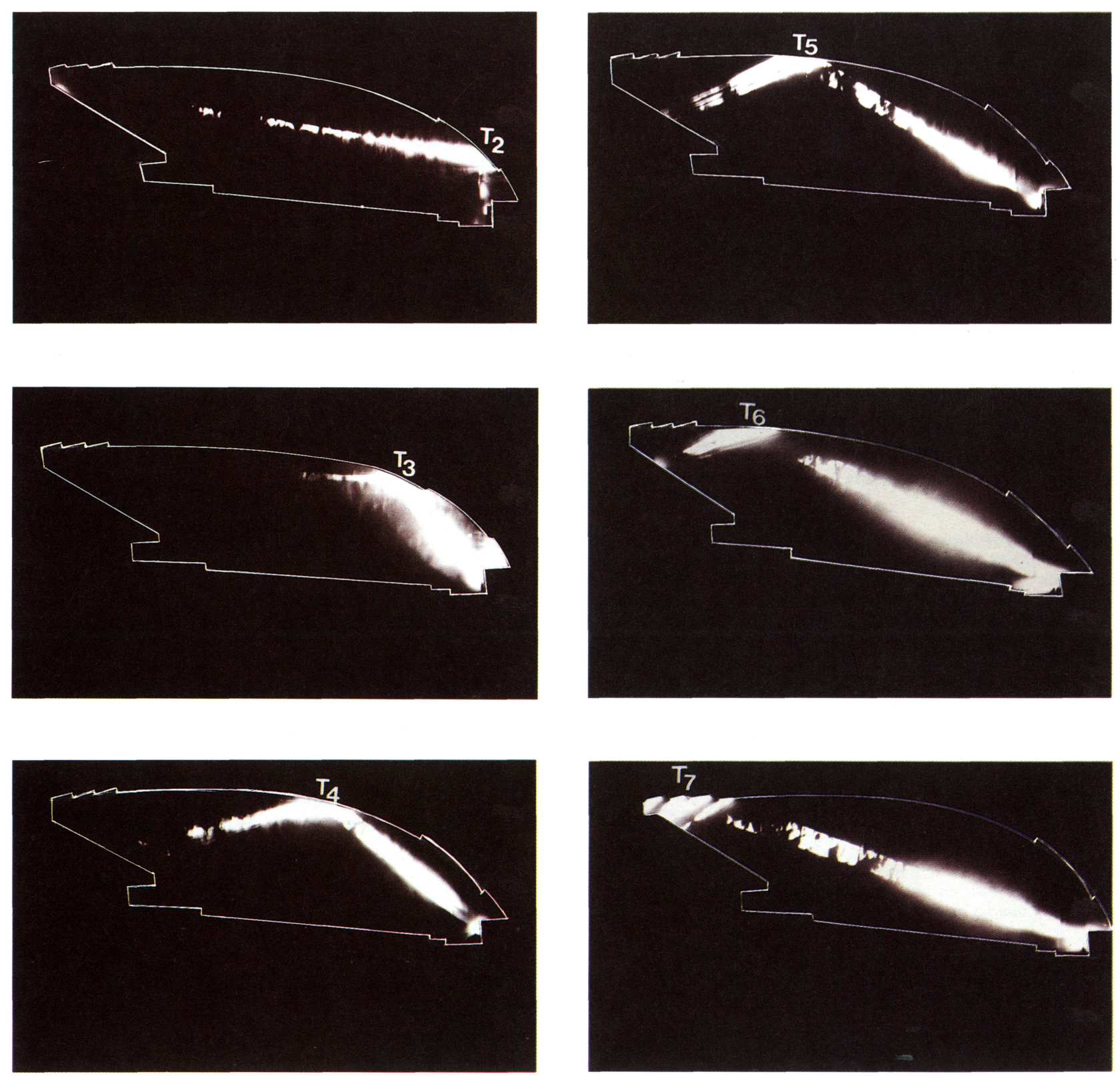

El estudio del Light-tracing en laboratorio sobre un modelo a escala reducida, ha permilido conocer mejor la aciustica previsla por Le Corbusier.

(c) Consejo Superior de Investigaciones Científicas 
A partir de la cual resultaría una curva continua semejante a la anterior y contenida dentro de un margen de 0,60 metros de anchura.

Se ha escogido el origen de coordenadas ubicado en el lugar del orador.

De acuerdo con esta curva, hemos comprobado que se conseguiría un reparto de la energía acústica reflejada bastante uniforme, pero insuficiente cuantitativamente hablando. En esta sala hace falta, además, tener en cuenta la absorción más fuerte de las frecuencias agudas que forman las consonantes, y que son fundamentales para la inteligibilidad de la palabra.

Debido a esto, la voz proveniente del orador, aun llegando a la tribuna del público como la suma del rayo directo más el reflejado en el techo, quedaría enmascarada por los sonidos de la propia sala.

Pero Le Corbusier no hace intervenir en su proyecto esta curva continua, sino que la rompe en seis segmentos y además la desplaza seis metros hacia abajo.

Quizá Le Corbusier, después de lo que hemos dicho, continuó con la esencia del método de Lyon y por lo tanto no sería de extrañar que se obtuviesen unas calidades y efectos similares a los que hemos señalado.

No obstante, no existe una curva matemática que defina esta segunda sección, y por eso se ha hecho el estudio con Light-tracing sobre modelo y·Ray-tracing sobre ACAD 12. Se observa que en muchos casos la energía reflejada se comporta de forma diferente a la del análisis gráfico del proyecto.

Esto nos lleva a preguntarnos si Le Corbusier no corrigió la curva del techo para enviar más energía sonora hacia las últimas filas.

\section{Conclusión}

En lo que se ha dicho hasta ahora, no se tiene que interpretar que la acústica de esta Sala sea deficiente. Ni mucho menos, porque con un pequeño incremento de megafonía hubiese quedado resuelto el tema de forma totalmente satisfactoria. Lo que ocurre es que confiar exclusivamente en el sistema utilizado era hacer aún poco al servicio de la acústica. Y, aun así, fijémonos en la polvareda que se levantó.

A lo que se debe llegar ahora, como consideración más importante a esta gran resonancia internacional, es que a partir de aquel momento la acústica de las grandes salas comenzó a ser tenida en cuenta como generadora de la propia forma de la arquitectura.

El planteamiento acústico de Le Cỏrbusier es correcto en esencia y muy innovador en su momento. Hasta hoy, matizado, es habitual en el diseño de salas que su sección resulte del estudio acústico.

Al considerar la acústica incluida de forma positiva en su proyecto, Le Corbusier nos dio una gran lección.
1. Giro Luigi Anzivino y Ezio Godoli (1979), Ginebra 1927: Il Concorso per il Palazzo della Società delle Nazioni e il caso Le Corbusier, Modulo Editrice, Firenze, pp. 82 y 83.

2. Ibíd., pp. 83 y 84 .

3. Francesc Daumal i Domènech (1990): LArchitecture Acoustique, un nouveau concept. Colloque de Physique. Colloque C2, supplément au numero 2, tome 51. Premier Congrès Français d'Acoustique. Les Éditions de Physique, Les Ulis, pp. c2-1059 a 1062.

4. Giro Luigi Anzivino y Ezi Godoli (1979): Opus cit., pp. 84 y 85.

5. José Pérez Miñana (1969): Compendio práctico de acústica aplicada. Editorial Labor, S.A., Barcelona, pp. 182 a 187.
6. Giro Luigi Anzivino y Ezi Godoli (1979): Opus cit., pp. 109.

7. Ibíd., pp. 92.

8. José Pérez Miñana (1969): Opus cit., pp. 432.

9. Le Corbusier (1928): La Salle Pleyel, une preuve de l'evolution architecturale. Cahiers d'Art, número 2, 1928. París, pp. 89 a 96.

10. Le Corbusier (24-5-1928): Une maison, un Palais; a la richerche d'une unité architecturale. Collection de l'esprit nouveau. Les éditons G. Grés et Cie. París, pp. 106 a 121.

11. Ibíd., pp. 104 a 107.

12. Boesiger, W.: Obra completa Le Corbusier (1910-1929). Édit $\mathrm{Y} / \mathrm{A}, \mathrm{pp} .162$ a 173 